\title{
Outcome and prognostic factors in Diffuse Large B-cell Lymphoma(DLBCL): An institutional experience of a tertiary care centre from India
}

Rohit Mahajan*, Budhi S Yadav, Ankita Gupta, Sushmita Ghoshal, Rakesh Kapoor, Narenrda kumar, S.C. Sharma

Department of Radiotherapy and oncology, PGIMER .

*Corresponding Author: Rohit Mahajan, Department of Radiotherapy and Oncology, MMIMSR, Mullana(Ambala), Email:rohit mahjn@yahoo.co.in, Tel: +919914411178.

Citation: Rohit Mahajan et al. Outcome and prognostic factors in Diffuse Large B-cell Lymphoma(DLBCL): An institutional experience of a tertiary care centre from India. Int J Cancer Epid \& Res.1:1, 6-10

Copyright: (C) 2017, Rohit Mahajan et al. 2017, This is an open-access article distributed under the terms of the Creative Commons Attribution License, which permits unrestricted use, distribution, and reproduction in any medium, provided the original author and source are credited.

Received February 24, 2017; Accepted March 10, 2017; Published March 17, 2017.

\section{Abstract}

Background: DLBCL is the most common non-Hodgkin's lymphoma(NHL). We conducted retrospective study in our institution to analyze the main clinical features at diagnosis, response to therapy and the outcome of patients with DLBCL.

Methods: This study enrolled 74 patients with histologically confirmed diagnosis of DLBCL treated from January 2003 to December 2014.Complete clinical patient and disease related details were recorded.All patients were treated with chemotherapy with or without radiotherapy.Clinical features, treatment response and impact of different prognostic factors on clinical outcome were analyzed.

Results: Median age of presentation was 50 years(range 18-85years). Ann Arbor clinical stage at diagnosis was 36(48.6\%) stage I,20(27\%) stage II, $13(17.6 \%)$ stage III, and 5(6.8\%) stage IV respectively. Nodal disease was present in $40(54.1 \%)$ patients and $34(45.9 \%)$ had extranodal disease presentation. Supradiaphragmatic disease was seen in 44(59.5\%) and $15(20.3 \%)$ had infradiaphragmatic as well as disease on both sides of the diaphragm. Most of the patients (93.2\%) received either CHOP or R-CHOP chemotherapy. Consolidative radiotherapy was received by $43(58.1 \%$ ) patients.Median follow-up period was 22 months(range 2-147 months).Complete response was seen in 51(68.9\%)patients. With addition of radiation,9.4\% improvement in local control was seen.Relapses was seen in 10(13.5\%) patients,out of which $5(6.8 \%)$ had nodal and 5(6.8\%) had visceral relapse.At 2-years, disease free survival (DFS) and overall survival (OS) was $66 \%$ and $81.5 \%$ respectively.Stage, IPI, supradiaphragmatic disease, number of sites, extranodal diasease and number of nodal sites involvement were important prognostic factors having significant impact on response, DFS and OS.

Conclusions: This study represents the largest Indian experience to treat DLBCL. Stage, IPI, supradiaphragmatic disease, number of sites, extranodal disease and number of nodal sites were the important prognostic factors for response, DFS and OS.

Key words: Outcome, prognostic factors, DLBCL

\section{Introduction}

Diffuse large B-cell lymphoma (DLBCL) is the most common non-Hodgkin's lymphoma(NHL), accounting for approximately $30 \%$ of all new diagnoses. 1 The cyclophosphamide, doxorubicin,

vincristine, and prednisolone(CHOP) chemotherapy regimen has been the mainstay of therapy since its development in the 1970 s. $^{2}$ Over the past few decades, chemotherapy consisting of the antiCD20 antibody rituximab combined most often with $\mathrm{CHOP}(\mathrm{R}-$ CHOP) has been established as the standard of care for patients with $\mathrm{DLBCL}^{3-6}$. Western literature has shown 5-year overall survival (OS) rates for patients with DLBCL varies from $45 \%$ to $82 \%{ }^{7-9}$. However, data from India is lacking. Thus, we conducted the retrospective study in our institution to analyze the main clinical features at diagnosis, response to therapy and the outcome of patients diagnosed with DLBCL.

\section{Materials and methods}

The retrospective study was conducted in our institution which enrolled 74 patients with histologically confirmed diagnosis of DLBCL treated from January 2003-December 2014. A complete history was recorded and physical examination including local examination of disease. Baseline investigations like complete blood count, blood biochemistry, chest x-rays, bone marrow biopsy and histopathological examination was done. All patients were biopsy proven for DLBCL. All patients underwent neck, 
chest, abdominal and pelvic computed tomography(CT) scans or positron emission tomography(PET) scan. Staging was done with CT/PET scans. All patients were treated with chemotherapy with or without radiotherapy. Clinical features, treatment response and impact of different prognostic factors on clinical outcome was analyzed.

\section{Results}

Patient characteristics: Median age of presentation was 50 years (range $18-85$ years). 55(74.3\%) of the patients were $<=60$ years age and $19(25.7 \%)$ were $>60$ years age. Out of 74 patients, 53 were males and 21 were females. Ann Arbor clinical stage at diagnosis was as follows: patients $36(48.6 \%)$ had stage I disease, 20 patients $(27 \%)$ had stage II disease, 13 patients $(17.6 \%)$ had stage III disease, and 5 patients $(6.8 \%)$ had stage IV disease. Bulky disease was defined as any mass greater than $10 \mathrm{~cm}$ in diameter; Bulky disease was present in 6 patients (8.1\%). 40(54.1\%) patients had nodal disease and $34(45.9 \%)$ had extranodal disease presentation. Supradiaphragmatic diasease was seen in 44(59.5\%) and $15(20.3 \%)$ each was found in infradiaphragmatic and on both sides of the diaphragm. Most of the patients(93.2\%) received either CHOP or R-CHOP chemotherapy. 43(58.1\%) patients received consolidative radiotherapy(30-40Gy). (Table1)

\section{Figure 1}

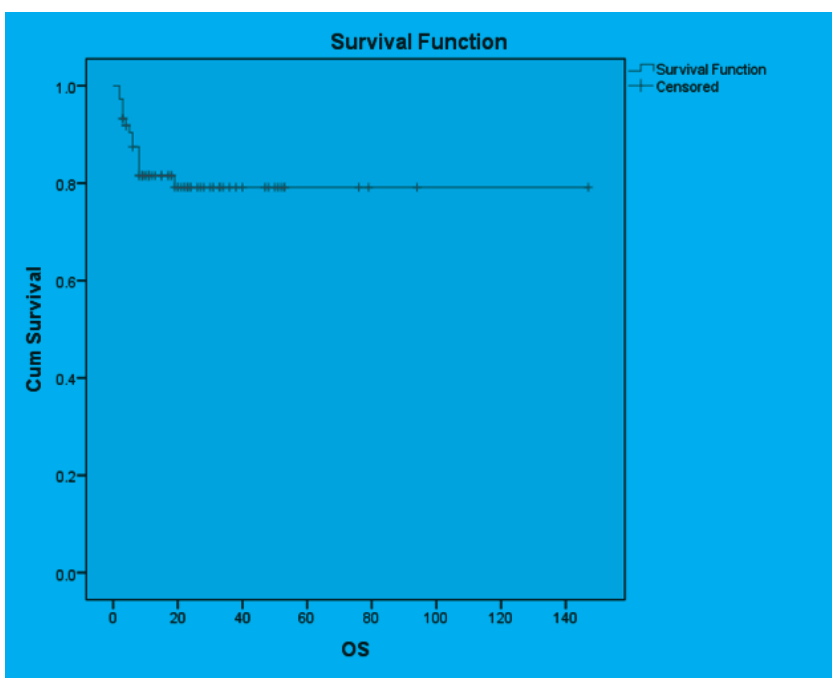

Response and survival: The median follow-up period was 24 months (range, 2 to 147 months). Complete response was seen in $51(69.0 \%$ ) patients. 9.4\% improvement in local control was seen with addition of radiation. Relapses was seen in $10(13.5 \%)$ patients, out of which 5(6.8\%) had nodal and 5(6.8\%) had visceral relapse. At 2 years, overall survival (OS) and disease free survival (DFS) was $81.5 \%$ and $66 \%$ respectively.(Table2,3) (Figure 1,2)

Prognostic factors: Stage, International prognostic index (IPI), Supradiaphragmatic disease, number of sites, extranodal diasease and number of nodal sites involvement were proven to be important prognostic factors having significant impact on local response, disease free survival (DFS) and overall survival (OS).(Table 4)

\section{Discussion}

In our study, we showed that there is marked improvement in local control of the disease with the addition of radiation to the CHOP/ R-CHOP chemotherapy. Despite the fact that R-CHOP is the standard chemotherapy regimen, we were able to give R-CHOP in only $21.6 \%$ patients due to poor affordability of most of the patients and thus, most of the patients $(71.6 \%)$ received CHOP chemotherapy. Involved field radiotherapy with the dose of 3040Gy was received in $58.1 \%$ patients after the chemotherapy

\section{Figure 2}

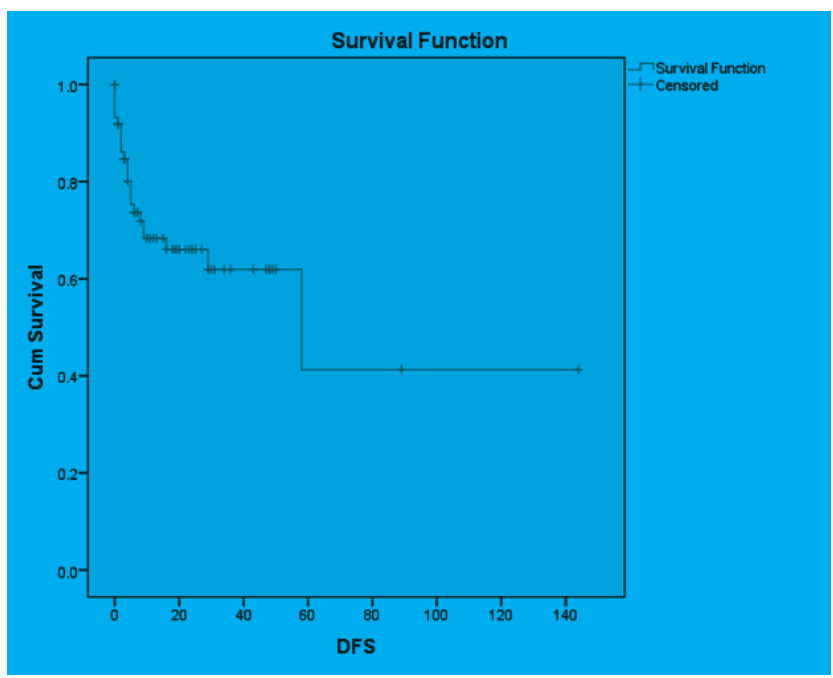


Table 1. Patient characteristics.

\begin{tabular}{|c|c|c|c|}
\hline Characteristic: & & Number & Percent \\
\hline \multirow[t]{2}{*}{ Age } & $<=60$ & 55 & 74.3 \\
\hline & $>60$ & 19 & 25.7 \\
\hline \multirow[t]{2}{*}{ Sex } & MALE & 53 & 71.6 \\
\hline & FEMALE & 21 & 28.4 \\
\hline \multirow[t]{2}{*}{ Site } & NODAL & 40 & 54.1 \\
\hline & EXTRANODAL & 34 & 45.9 \\
\hline \multirow[t]{2}{*}{ Nodal sites } & $<4$ & 34 & 45.9 \\
\hline & $=>4$ & 6 & 8.1 \\
\hline \multirow[t]{2}{*}{ B symptoms } & NO & 70 & 94.6 \\
\hline & Yes & 4 & 5.4 \\
\hline \multirow[t]{2}{*}{ Bulky disease } & NON BULKY & 68 & 91.9 \\
\hline & BULKY & 6 & 8.1 \\
\hline \multirow[t]{3}{*}{ Location } & $\begin{array}{l}\text { SUPRADIAPHRAG- } \\
\text { MATIC }\end{array}$ & 44 & 59.5 \\
\hline & $\begin{array}{l}\text { INFRADIAPHRAGMAT- } \\
\text { IC }\end{array}$ & 15 & 20.3 \\
\hline & BOTH & 15 & 20.3 \\
\hline \multirow[t]{4}{*}{ Number of sites } & ONE & 40 & 54.1 \\
\hline & TWO & 22 & 29.7 \\
\hline & THREE & 7 & 9.5 \\
\hline & FOUR OR MORE & 5 & 6.8 \\
\hline \multirow[t]{2}{*}{ Bone marrow } & NOT INVOLVED & 70 & 94.6 \\
\hline & INVOLVED & 4 & 5.4 \\
\hline \multirow[t]{4}{*}{ Stage } & I & 36 & 48.6 \\
\hline & II & 20 & 27.0 \\
\hline & III & 13 & 17.6 \\
\hline & IV & 5 & 6.8 \\
\hline \multirow[t]{3}{*}{ IPI } & LOW & 58 & 78.4 \\
\hline & INTERMEDIATE & 9 & 12.2 \\
\hline & HIGH INTERMEDIATE & 7 & 9.5 \\
\hline \multirow[t]{2}{*}{ Treatment } & CCT & 31 & 41.9 \\
\hline & $\mathrm{CCT}+\mathrm{RT}$ & 43 & 58.1 \\
\hline \multirow[t]{5}{*}{ Chemotherapy } & $\mathrm{CHOP}$ & 53 & 71.6 \\
\hline & COP & 3 & 4.1 \\
\hline & $\mathrm{RCHOP}$ & 16 & 21.6 \\
\hline & DEANGALE & 1 & 1.4 \\
\hline & TMZ & 1 & 1.4 \\
\hline
\end{tabular}


Table 2. Disease status

\begin{tabular}{|c|c|c|c|}
\hline Status & CR & 51 & 68.9 \\
\hline & PR & 7 & 9.5 \\
\hline & SD & 2 & 2.7 \\
\hline & PD & 13 & 17.6 \\
\hline Relapse & LTFU & 1 & 1.4 \\
\hline & nodal & 5 & 6.8 \\
\hline
\end{tabular}

Table 3.

\begin{tabular}{|r|r|}
\hline Relapse: & Number(\%) \\
\hline Nodal & $5(6.8)$ \\
\hline Visceral & $5(6.8)$ \\
\hline
\end{tabular}

Table 4. Prognostic factors:

\begin{tabular}{|c|c|c|c|}
\hline & Local control(p value) & DFS(p value) & OS(p value) \\
\hline Age $(<60 />60)$ & 0.599 & 0.515 & 0.346 \\
\hline Sex(M/F) & 0.724 & 0.234 & $\mathbf{0 . 0 3 6}$ \\
\hline Stage(I,II/ III,IV) & $\mathbf{0 . 0 0 8}$ & $\mathbf{0 . 0 0 7}$ & $\mathbf{0 . 0 4 8}$ \\
\hline $\begin{array}{c}\text { International prognostic index (IPI)(Low/ } \\
\text { Intermediate High,High) }\end{array}$ & $\mathbf{0 . 0 3 3}$ & $\mathbf{0 . 0 1 0}$ & $\mathbf{0 . 0 1 0}$ \\
\hline Supradiaphragmatic disease(Yes/No) & $\mathbf{0 . 0 1 3}$ & $\mathbf{0 . 0 0 9}$ & $\mathbf{0 . 0 4 5}$ \\
\hline Number of sites(1,2/3,4) & $\mathbf{0 . 0 4 2}$ & 0.182 & $\mathbf{0 . 0 3 4}$ \\
\hline Extranodal diasease(Yes/No) & 0.916 & $\mathbf{0 . 0 4 4}$ & 0.745 \\
\hline Number of nodal sites involvement(<4/>4) & $\mathbf{0 . 0 4 9}$ & $\mathbf{0 . 0 0 5}$ & $\mathbf{0 . 0 0 1}$ \\
\hline B symptoms(Yes/No) & 0.693 & 0.344 & 0.885 \\
\hline Bulky disease(Yes/No) & 0.159 & 0.128 & 0.935 \\
\hline Radiation(Yes/No) & 0.458 & 0.808 \\
\hline Chemotherapy(CHOP/RCHOP) & & & 0.936 \\
\hline
\end{tabular}


completion. At 2 years, overall survival(OS) and disease free survival(DFS) was $81.5 \%$ and $66 \%$ respectively. In the present study with a median follow-up time of 2 years, we found that disease free and overall survival estimates among patients treated with chemotherapy alone did not differ from those observed among patients treated with chemotherapy plus radiotherapy. In our study, 9.4\% improvement in local control was seen with addition of radiation, however, it was not statistically significant. Of note, we observed a lack of difference in outcome for the 6 patients with bulky disease, a condition in which adjuvant radiotherapy is believed to optimally control local disease ${ }^{10,11}$; however, this must be interpreted cautiously because of the small size of this subset of patients. An update of study by Miller et al with a longer followup showed that survival curves ultimately converged as a result of an excess of lymphoma relapses in the CHOP plus radiotherapy group. ${ }^{12}$ Horning et al13 recently reported the results of a study with a median follow-up of 12 years in which patients with limitedstage aggressive lymphoma received consolidative radiotherapy after eight cycles of $\mathrm{CHOP}$ in which radiotherapy provided good local control which was similar in our study which showed improved local control of the disease by $9.4 \%$ with the addition of radiation although there was no significant benefit in OS. At 2 years estimated OS rates were $91 \%$ for CR patients consolidated with radiation ${ }^{13}$ which was $81.5 \%$ in our study. Multiple prognostic factors were analyzed in our study where stage, International prognostic index (IPI), Supradiaphragmatic disease, number of sites, extranodal diasease and number of nodal sites involved were proven to be statistically significant factors having impact on local response, disease free survival (DFS) and overall survival (OS) whereas Bonnet et al in his study showed that overall survival was affected by stage II disease $(p<0.001)$; and male sex $(p<0.03)$ but not by bulky disease $(\mathrm{p}<0.3)$; event-free survival was affected only by stage II disease $(p<0.001)$. Among the total of 576 patients, 5 -year event-free and overall survival rates were $70 \%$ and $76 \%$ for patients with stage I disease, respectively, and $49 \%$ and $58 \%$ for patients with stage II disease, respectively.

\section{Conclusion}

This study represents the largest Indian experience to treat DLBCL. Stage, IPI, supradiaphragmatic disease, number of sites, extranodal disease and number of nodal sites came out to be the important prognostic factors for response, DFS and OS.

\section{References}

1. Jaffe ES, Harris NL, Stein H, et al: World Health Organization Classification of Tumors: Pathology and Genetics of Tumors of Haematopoietic and Lymphoid Tissues. Lyon, France, IARC Press, 2001

2. McKelvey EM, Gottlieb JA, Wilson HE, et al: Hydroxyl daunomycin (Adriamycin) combination chemotherapy in malignant lymphoma. Cancer 38:1484-1493, 1976

3. Coiffier B, Lepage E, Briere J, et al: CHOP chemotherapy plus rituximab compared with $\mathrm{CHOP}$ alone in elderly patients with diffuse large-B-cell lymphoma. N Engl J Med 346:235-242, 2002

4. Habermann TM, Weller EA, Morrison VA, et al: RituximabCHOP versus CHOP alone or with maintenance rituximab in older patients with diffuse large B-cell lymphoma. J Clin Oncol $24: 3121-3127,2006$

5. Pfreundschuh M, Trumper L, Osterborg A, et al: CHOP-like chemotherapy plus rituximab versus CHOP-like chemotherapy alone in young patients with good-prognosis diffuse large-B cell lymphoma: A randomised controlled trial by the MabThera International Trial (MInT) Group. Lancet Oncol 7:379-391, 2006

6. $\mathrm{Ng} \mathrm{AK}$, Mauch PM: Role of radiation therapy in localized aggressive lymphoma. J Clin Oncol 25:757-759, 2007

7. Miller TP, Dahlberg S, Cassady JR, et al: Chemotherapy alone compared with chemotherapy plus radiotherapy for localized intermediate- and high-grade non-Hodgkin's lymphoma. N Engl J Med 339:21-26, 1998

8. Ballonoff A, Rusthoven KE, Schwer A, et al: Outcomes and effect of radiotherapy in patients with stage I or II diffuse large B-cell lymphoma: A surveillance, epidemiology, and end results analysis. Int J Radiat Oncol Biol Phys 72:1465-1471, 2008

9. Feugier P, Van Hoof A, Sebban C, et al: Long-term results of the R-CHOP study in the treatment of elderly patients with diffuse large B-cell lymphoma: A study by the Groupe d'Etude des Lymphomes de l'Adulte. J Clin Oncol 23:4117-4126, 2005

10. Zinzani PL, Martelli M, Magagnoli M, et al: Treatment and clinical management of primary mediastinal large B-cell lymphoma with sclerosis: MACOP-B regimen and mediastinal radiotherapy monitored by (67) Gallium scan in 50 patients. Blood 94:3289-3293, 1999

11. Connors J: Principles of chemotherapy and combined modality therapy, in Mauch P, Armitage J, Coiffier B, et al (eds): NonHodgkin's Lymphomas. Philadelphia, PA, Lippincott Williams \& Wilkins, 2004, pp 201-219.

12. Miller TP, Leblanc M, Spier CM, et al: CHOP alone compared to $\mathrm{CHOP}$ plus radiotherapy for early stage aggressive nonHodgkin's lymphomas: Update of the Southwest Oncology Group (SWOG) randomized trial. Blood 98:S742-S743, 2001 (suppl).

13. Horning SJ, Weller E, Kim K, et al: Chemotherapy with or without radiotherapy in limited-stage diffuse aggressive nonHodgkin's lymphoma: Eastern Cooperative Oncology Group Study 1484. J Clin Oncol 22:3032-3038, 2004. 